\title{
Modelação Matemática e atividade profissional como prática em sala de aula: metodologia ativa no Ensino de Matemática
}

\section{Mathematical Modeling and professional activity as a classroom practice: active methodology in Mathematics Teaching}

\author{
Rodolfo Magliari de Paiva ${ }^{1}$ \\ Evanilton Rios Alves ${ }^{2}$ \\ Marilena Souza Rosalen ${ }^{3}$
}

\begin{abstract}
Resumo: A Matemática é vista por grande parte dos alunos como algo que não possui utilidade prática no dia a dia. Com base nisso, se o professor trouxer para a sala de aula a Modelação Matemática por meio de atividades profissionais que fazem uso da Matemática, em forma de Metodologia Ativa, acreditamos que possibilitará aos alunos uma vivência desta e possivelmente torná-la mais atrativa. O objetivo da proposta é contribuir para a formação inicial e continuada de professores de Matemática para a Educação Básica. A pesquisa de referência teve como Metodologia a Pesquisa Qualitativa, e como técnica de coleta de dados, a entrevista com marceneiros. Os resultados sugerem que a escola desenvolva projetos de modo a aproveitar o conhecimento matemático de atividades profissionais.
\end{abstract}

Palavras-chave: Modelação Matemática. Metodologia Ativa. Ensino de Matemática. Formação de Professores.

\begin{abstract}
Mathematics is seen by most students as something that has no practical use in their daily lives. Based on this, if the teacher brings Mathematical Modeling to the classroom through professional activities that make use of Mathematics, in the form of Active Methodology, we believe that it will enable students to experience it and possibly make it more attractive. The purpose of the proposal is to contribute to the initial and continued training of Mathematics teachers for Basic Education. The reference research used Qualitative Research as a methodology, and as a data collection technique, interviews with

\footnotetext{
${ }^{1}$ Mestrando em Ensino de Ciências e Matemática, UNIFESP. E-mail: rodolfomagliari@gmail.com

${ }^{2}$ Mestre em Ensino de Matemática, PUC. E-mail: era.matematica@gmail.com

${ }^{3}$ Doutora em Educação, UNIFESP. E-mail: marilena.rosalen@unifesp.br
}

Recebido em 23/01/2022

Aprovado em 10/02/2022

Sistema de Avaliação: Double Blind Review

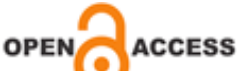


cabinetmakers. The results suggest that the school develop projects in order to take advantage of mathematical knowledge from professional activities.

Keywords: Mathematical Modeling. Active Methodology. Teaching of Mathematics. Teacher Training.

\section{Introdução}

A Matemática é vista por grande parte dos alunos como algo que não possui utilidade prática no dia a dia, tão pouco como algo que tenha relação direta com a prática de alguém, ou com alguma área e com alguma profissão, fato este que chama muito a atenção, dada a ampla rede de aplicações da Matemática no mundo contemporâneo desde as civilizações antigas.

Diante desse cenário, é muito comum o educador matemático ouvir de seus alunos ao longo de suas aulas perguntas como "onde usarei isso na minha vida?", ou ainda "para que serve isso?". Neste momento o professor de matemática se vê em uma posição, muitas vezes desconfortável e fornece respostas como "a Matemática está em tudo", ou ainda "sem Matemática não teríamos os celulares", entre outras respostas "superficiais", que acabam não convencendo os alunos de sua utilidade, visto que, apesar do profissional ser educador matemático, não faz parte da sua formação conhecer a aplicação da Matemática de forma prática, como em cursos de Engenharia, por exemplo.

Isto, possivelmente, contribui para que os alunos não vejam a Matemática como algo interessante e importante de ser estudada e aprendida, fazendo com que se desanimem com esta unidade curricular e adquiram resistência à mesma.

Vale destacar neste ponto, que isso não ocorre apenas com a Matemática, ou seja, não é exclusivo da Matemática. Porém, a Matemática é a unidade curricular que apresenta maior ausência aparente de relação e correlação com o mundo de forma mais acentuada, ainda que saibamos que a Matemática não é estudada apenas para "o que serve”, no sentido de uma aplicação concreta. Dentre suas importâncias, podemos destacar o seu papel no desenvolvimento dos raciocínios lógico, abstrato e concreto, sendo um componente muito importante para o desenvolvimento das competências e habilidades de crianças e jovens durante o ciclo da Educação Básica, conforme também apontado na BNCC. 


\section{Modelagem Matemática x Modelação Matemática}

Antes de falarmos sobre a Modelação Matemática e sua conexão com a Atividade Profissional, é interessante sabermos a diferença entre dois conceitos comumente interpretados como sinônimos: Modelagem Matemática e Modelação Matemática.

A Matemática foi, e, continua sendo desenvolvida a partir das necessidades de uma sociedade para resolver problemas, sendo assim, a área da Matemática que estuda sistemas reais a fim de prever e descrever seus comportamentos é chamada de Matemática Aplicada, e possui diversas aplicações em outras áreas, como na Física, Química, Biologia, Economia, Engenharias, etc. Os pesquisadores desenvolvem modelos matemáticos que descrevem uma aproximação do problema real (simulação), modelos estes que não são simples, dadas as suas complexidades, com isso, a grosso modo, pode-se dizer que a Matemática e a realidade são dois conjuntos disjuntos, e a modelagem é um meio de fazê-las interagir (BIEMBENGUT, 1999).

A Modelagem Matemática visa descrever um problema real, modelando o problema por meio de um modelo aproximado. Deste problema aproximado, é possível obter soluções reais. Ou seja, o processo de modelagem matemática consiste na arte de transformar problemas da realidade em problemas matemáticos e de resolvê-los interpretando suas soluções na linguagem do mundo real (BASSANEZI, 2014), e é possível utilizar este conceito (modelagem matemática), como estratégia pedagógica em sala de aula.

Já a Modelação Matemática, para BIEMBENGUT (1999), é um método que utiliza a essência da Modelagem Matemática para cursos regulares onde há um programa a ser cumprido (currículo), além de levar em consideração o grau de escolaridade dos alunos, tempo disponível para trabalharem extra-classe, além do conhecimento do professor.

\section{Modelação Matemática e Atividade Profissional}

Com base no que foi apontado anteriormente, dentre tantas possibilidades que o professor de Matemática poderia escolher para que, aos poucos, o obstáculo na apredizagem da Matemática possa ser superado, uma proposta possível é que, se o educador matemático trouxer para a sala de aula a Modelação Matemática por meio de atividades profissionais que fazem uso da Matemática, como Engenharia, Arquitetura, Estatístca, Administração, 
Economia, Contabilidade, Ciência de Dados, Programação, Epidemiologia, Biomedicina, Consultoria, Inteligência de Mercado, etc, em forma de Metodologia Ativa, acreditamos que possibilitará aos alunos uma vivência desta e possivelmente torná-la mais atrativa e até melhor compreendida, visto que, os alunos terão contato com atividades profissionais e também com profissionais do mercado de trabalho, que poderão responder em detalhes para que servem determinados objetos ou entes da Matemática que são aprendidos durante o ciclo da Educação Básica de forma prática.

\section{Metodologia Ativa}

Quando falamos do processo de ensino e aprendizagem, um tema que vem sendo muito discutido é o das Metodologias Ativas. A ideia central das Metodologias Ativas é romper o modelo tradicional, que utiliza "metodologias passivas", tirando o professor como protagonista e detentor de todo o conhecimento, fazendo consequentemente com que o aluno vire um depósito de informações; e colocando o aluno em ação (protagonista e responsável pela sua aprendizagem), visto que agora o professor é um mediador.

Vale lembrar que a palavra "metodologia" refere-se aos caminhos que o professor utilizará para a realização de suas aulas, ou seja, para a construção do conhecimento com os seus alunos. Já o termo "aprendizagem ativa", começou a ser utilizado pelo professor inglês R.W. Revans, durante a década de 1930, e a proposta é de utilizar modelos que enfatizem as experiências de aprendizado com significado e na prática, como atividades que estimulam debate, estudos de caso, reflexões, o raciocínio lógico, deduções, ou seja, atividades que melhoram o relacionamento interpessoal do aluno e também a sua capacidade de expressão.

A união desses termos, no que hoje chamamos de Metodologias Ativas, representa uma maneira nova de pensar o ensino, indo ao encontro do que é observado na Pirâmide de Aprendizagem de William Glasser, onde os três níveis inferiores que compõem a base da pirâmide, do menor ao maior, são respectivamente: Discutir, Praticar, Ensinar a Outros, sendo classificados como aprendizagem ativa, enquanto que os demais níves da pirâmide são clasificados como aprendizagem passiva.

Com isso, podemos apontar que metodologias ativas são estratégias de ensino centradas na participação efetiva dos estudantes na construção do processo de aprendizagem, de forma flexível, interligada e híbrida (BACICH, MORAN, 2018). 


\section{A proposta}

O objetivo da proposta é contribuir para a formação inicial e continuada de professores de Matemática para a Educação Básica, estimulando o docente para que traga, no contexto da sala de aula, uma atividade profissional para ser estudada de modo que seja possível unir a Matemática formal (aquela aprendida no ambiente acadêmico), com a informal (aquela aprendida por meio da prática), ao compreender quais entes matemáticos estão envolvidos na atuação profissional em questão, saindo do modelo tradicional. A questão que norteou a pesquisa foi: Qual a matemática desenvolvida com a atividade de marceneiro?

O estudo de referência teve como Metodologia a Pesquisa Qualitativa, e como técnica de coleta de dados, a entrevista com 06 (seis) marceneiros (atividade profissional escolhida), em locais e horários diferentes (espaços diferentes), de modo a evitar o contato entre os participantes, que foram contatados por indicação ou conhecimento pessoal, e que atuam na Grande São Paulo e interior do Estado.

As entrevistas ocorreram entre o início de janeiro de 2005 até o final de fevereiro de 2005, e os registros das entrevistas foram gravados em fitas K-7. A entrevista foi feita de forma estruturada (padronizada), utilizando um roteiro de questões previamente preparadas.

Entre as respostas dos participantes, os objetos matemáticos identificados foram: metro linear, metro quadrado, metro cúbico, ângulo, soma, subtração, multiplicação, divisão, Teorema de Pitágoras, trigonometria no triângulo retângulo e matemática financeira, entre outros onjetos.

Foi observado que apesar de saberem efetuar os cálculos e utilizar os objetos matemáticos para o seu trabalho, muitos não se lembravam mais das fórmulas e dos nomes técnicos dos objetos matemáticos que aprenderam na escola e que na época utilizavam, o que nos remete ao saber formal versus o saber informal, ou seja, boa parte do que é desenvolvido na escola com relação à cientificidade, desde definições e termos científicos, não são necessariamente compreendidos, aponta Alves, 2006; deste modo o trabalho é desenvolvido pelos marceneiros, mas não existe a preocupação do conhecimento dos nomes técnicos e outros conhecimentos acadêmicos da escola tradicional, ainda pois, dentre os participantes, alguns não aprenderam matemática, que utilizam no trabalho, no ambiente escolar. A pesquisa ainda aponta que a Matemática da escola é uma e não aplicada à realidade, fazendo com que se tenha a impressão de que existam matemáticas diferentes. 
Com isso, os objetos matemáticos identificados a partir das entrevistas, de acordo com ALVES, 2006, que o professor de Matemática pode abordar em sala de aula, a partir da atividade profissional de marcenaria são:

\section{1 Ângulos}

- ângulos e classificações;

- inclinação.

\subsection{Reta}

- reta;

- segmento de reta;

- paralelismo;

- mediatriz;

- perpendicularismo;

- extremidades;

\subsection{Circunferência}

- centro;

- circunferência;

- cordas;

- arco.

\subsection{Perspectiva Isométrica}

- visão cônica (humana);

- profundidade e relevo;

- dimensões;

- representação gráfica;

- tipos de perspectivas;

- projeção.

\subsection{Perspectiva Cavaleira}

- ideias de Perspectiva Cavaleira;

- medidas;

- medida horizontal e medida vertical;

- inclinação;

- superfícies curvas.

\subsection{Escala}

- escala;

- proporção;

- conceito entre o real e o desenho técnico;

- redução e ampliação.

\subsection{Aspectos Ergonômicos do Móvel}

- unidade de medida;

- desenho (planta baixa);

- quadrilátero.

1.8 Perspectiva Exata - 2 Pontos de Fuga

- perspectiva exata;

- ponto de fuga;

- área;

- largura;

- altura;

- aritmética;

- percentagem.

Todas elas se conectando, de forma prática e alinhadas com a realidade, de modo que o estudante perceba a utilidade destes objetos matemáticos.

\section{Um pouco além}

A atividade profissional escolhida, marcenaria, faz parte do setor da Construção Civil, e por esta pequena amostra, já foi possível perceber boa parte dos objetos matemáticos que é possível trabalhar em sala de aula com os alunos, durante o ciclo da Educação Básica.

Se expandirmos essa proposta para outras áreas, como as Engenharias, por 
exemplo, as possibilidades serão ainda maiores, seria necessário apenas definir qual Engenharia seria tomada como atividade profissional, visto que existem diversas, de modo a fazer apoximações de conteúdos, não somente da Matemática, mas também da Física e da Química, de forma multidisciplinar!

Acreditamos que, dado o momento da Indústria 4.0 que estamos vivendo, a chamada Quarta Revolução Industrial, com o surgimento e desenvolvimento da Inteligência Artificial, Big Data, Ciência de Dados, Internet of Things, utilizar destas áreas como aproximação de conteúdos pertinentes a Estatística e Linguagem de Programação, por exemplo, também seria de muita valia e bem oportuno.

\section{Considerações finais}

Os resultados sugerem que a escola desenvolva projetos de modo a aproveitar o conhecimento matemático de atividades profissionais, afim de estabelecer uma relação entre a Matemática que é ensinada na escola (acadêmica), com a Matemática de atividades profissionais (não acadêmica), tornando-a mais concreta e próxima dos alunos.

Acreditamos que esta é uma proposta que contribui para o processo de ensino e aprendizagem da Matemática, provocando também reflexões na prática pedagógica do educador matemático em sala de aula, visto que, este também irá aprender com outros profissionais.

Por fim, vale ressaltar que esta proposta é apenas uma, dentre outras disponíveis na literatura que contribuem para a formação continuada do professor de matemática e também para o rompimento dos obstáculos dos alunos na aprendiagem da Matemática.

\section{Referências}

ALVES, Evanilton R. Atividade de Marcenaria e Etnomatemática: Possibilidades num contexto de Formação de Professores. São Paulo: PUC-SP, 2006. 97p.

(Dissertação, mestrado em Ensino de Matemática).

ALVES, Evanilton R. Etnomatemática - Multiculturalismo em sala de aula: a atividade profissional como prática educativa. São Paulo: Porto de Ideias, 2010. 


\section{REVISTA MULTIDISCIPLINAR}

ISSN 1809-1628

BACICH, Lilian. MORAN, José. Metodologias Ativas para uma educação inovadora: Uma abordagem teórico-prática. Porto Alegre: Penso, 2018.

BASSANEZI, Rodney C. Ensino-Aprendizagem com Modelagem Matemática. São Paulo: Contexto, 2014.

BIEMBENGUT, Maria S. Modelagem Matemática \& Implicações no EnsinoAprendizagem de Matemática. Santa Catarina: Furb, 1999. 